\title{
Japan's 2014 Strategic Energy Plan: A Planned Energy System Transition
}

\author{
Jeffrey B. Kucharski and Hironobu Unesaki \\ Graduate School of Energy Science, Kyoto University, Kyoto, Japan \\ Correspondence should be addressed to Jeffrey B. Kucharski; jeffok7@gmail.com
}

Received 13 February 2017; Accepted 11 May 2017; Published 12 June 2017

Academic Editor: Umberto Desideri

Copyright (c) 2017 Jeffrey B. Kucharski and Hironobu Unesaki. This is an open access article distributed under the Creative Commons Attribution License, which permits unrestricted use, distribution, and reproduction in any medium, provided the original work is properly cited.

\begin{abstract}
This study is a review and analysis of the Japanese government's 2014 Strategic Energy Plan (SEP). As the first plan to be issued after the Fukushima disaster of March 2011, the 2014 plan incorporates policies that represent the most comprehensive and systematic changes ever proposed for Japan's energy system. The study reviews the key elements of the plan, employing a framework that explains the nature and magnitude of the changes planned for Japan's energy system and related institutions. The analysis demonstrates that the shock of the triple disaster opened up a window of opportunity in Japan's policy environment for a fundamental change in energy policy, allowing for major reforms to the energy industrial structure and energy institutions. A unique aspect of this study is that it draws upon in-person interviews conducted with key government officials who were directly involved in the formulation of the SEP, providing new insights into Japan's energy policy planning process and the drivers behind the planned reforms. Given the nature and magnitude of the potential changes implied in the SEP, this paper concludes that the 2014 SEP is best understood as a comprehensive blueprint toward a major planned transition of the Japanese energy system.
\end{abstract}

\section{Introduction}

On April 11, 2014, the Japanese Cabinet approved the 2014 Strategic Energy Plan (SEP). This was the fourth such plan to be issued by the government. In a statement accompanying the announcement of the plan's approval, the government stated that the 2014 plan would form "the basis for the orientation of Japan's new energy policy, considering the dramatic changes in energy environments inside and outside Japan, including those caused by the Great East Japan Earthquake and the subsequent accidents at Tokyo Electric Power Company's (TEPCO) Fukushima Daiichi Nuclear Power Station" [1]. As the first plan to be issued after the disastrous events of March 2011, the 2014 plan embodies the most comprehensive and systematic changes ever proposed for Japan's energy system.

While many studies have examined aspects of Japanese energy policy, there have been very few detailed analyses of Japan's Strategic Energy Plans. Duffield and Woodall [2] described Japan's 2010 Basic Energy Plan $\left(\mathrm{BEP}^{1}\right)$ in detail and analyzed the appropriateness and feasibility of its goals and targets using a descriptive approach.
In the period preceding the development of the 2014 SEP, a number of studies examined the implications of the Fukushima disaster for Japanese energy policy, including [3-10]. Some studies have examined specific policies in the context of the 2014 SEP including fuel cell and hydrogen development policies [11, 12], the implications for climate change [13-15], nuclear power policy $[5,16]$, and energy system resilience [3].

Despite the fact that the 2014 SEP represents a major revision compared to previous energy plans and proposes groundbreaking energy system reforms, there has not yet been any systematic analysis of the plan and the implications for system transition in the academic literature. The purpose of this paper is therefore to explain the key features of the 2014 Strategic Energy Plan and to provide an analysis that explains its significance for energy system change in Japan.

The structure of this study begins with a summary of the key drivers, goals, strategies, and policy instruments proposed in the plan. This is followed by a discussion of relevant theory and the development of a theory-based analytical framework for the analysis. This framework relies upon the literature on sociotechnical transitions and theories of policymaking as social learning. The analysis itself begins by 
comparing the 2014 plan with previous plans and discusses the relationship to other government plans and policies. A background to the development of the plan, including the key motivations and drivers that shaped its development, is provided followed by a content analysis that discusses the nature and degree of change implied in the plan. Finally, we evaluate the overall significance of the 2014 SEP for energy system change and discuss the implications for structural and institutional reform in Japan's energy sector.

A unique aspect of this study is that it draws upon inperson interviews conducted with senior government officials who were directly involved in the formulation of the SEP, providing new insights into Japan's energy policy planning process and the drivers behind the policies embodied in the plan.

\section{Background: The 2014 Strategic Energy Plan}

The 2002 Basic Act on Energy Policy prescribes that a Basic Energy Plan be issued at least every 3-4 years. The first such plan was issued in 2003, and subsequent plans were issued in 2007, 2010, and 2014. The 2014 Strategic Energy Plan ${ }^{2}$ is therefore the fourth such plan to be issued and is by far the most detailed and comprehensive to date. This section reviews the major policies, strategies, and elements of the 2014 SEP.

2.1. Key Assumptions and Drivers of Policy. The introductory section of the plan begins by laying out a wide array of potential threats and challenges facing Japan's energy system. The plan stresses the "harsh" environment threatening Japan's energy security and states that Japan faces a "fundamental vulnerability" as a result of its need to import almost all its energy resources. Energy security concerns include increased dependency on the Middle East for fuel imports, resource competition and rising fuel prices, and increased greenhouse gas (GHG) emissions. Domestic challenges include those related to nuclear power plant safety, rising electricity prices and structural issues in electricity markets.

The plan views the Great East Japan Earthquake, tsunami, and accident at the Fukushima Daiichi nuclear power plant (henceforth referred to as the "triple disaster") as a major turning point, stating that an affordable and stable electricity supply cannot be secured simply by maintaining the electricity supply system of the past. It acknowledges that the circumstances surrounding energy "changed drastically" after the disaster, leading to a "new direction" for Japanese energy policy. It acknowledges the "safety myth" that was prevalent in Japan's nuclear establishment, the lack of attention to safety that led to the failure to prevent the Fukushima disaster, and the ongoing need for recovery and reconstruction efforts in Fukushima.

The stated intent of the plan is to give policy direction for changes in Japan's energy system over the medium to long term ( 20 years). The plan mentions that Japan will "minimize its dependency on nuclear power" as a "starting point" for the reformulation of Japan's energy policy. The period between 2018 and 2020 is seen as a period of intensive structural reform in the energy sector as domestic electricity reform measures take hold and new, more stable and secure supplies of energy resources become available (i.e., shale gas).

2.2. Principles and Objectives. The SEP is built around two key principles that guide energy policy. These principles are premised on the notion that Japan's economic development cannot be sustained without "establishing an energy supplydemand structure that realizes a stable energy supply system which imposes a light burden on society."

In this vein, the " $3 \mathrm{E}+\mathrm{S}$ " principle emphasizes the primacy of ensuring energy security while also improving economic efficiency and environmental "suitability," with safety (S) as a basic premise. This principle is already embodied in Japan's Basic Act on Energy Policy and its inclusion in the SEP is a reconfirmation of its role in guiding energy policy development.

The second principle is aimed at building a "multilayered, flexible, and diversified energy supply-demand structure." This is primarily concerned with establishing a welldiversified and well-balanced portfolio of energy sources in the electricity generation mix whereby the strengths and weaknesses of various fuels are combined to achieve maximum efficiency and low cost.

2.3. The Energy Supply-Demand Structure. In addition to the two basic principles, the strategy outlines the government's perspective on the primary and secondary energy supplydemand structure.

Regarding the primary energy supply structure, various energy sources are prioritized and positioned mainly in terms of their role as electricity supply sources. The plan views nuclear and coal generation as "base-load" power sources, natural gas as an "intermediate" power source, and oil and pumped hydro as "peaking" power sources.

The secondary energy structure is defined primarily in terms of demand-side issues. Here, the government acknowledges the central role of electricity generation and the expansion of electrification in the economy, emphasizing the need to "maximize" efficiency by conducting further research into the efficient conversion of energy into electricity and heat while reducing waste and losses. Hydrogen is also seen as playing a major role as a secondary energy carrier in the future. The plan reiterates Japan's "inability" to exchange power with neighboring countries, and calls for establishing a well-balanced wide-area grid so that electricity can be utilized more efficiently on a national basis. The plan also anticipates that major structural changes will be required in electricity markets in order to meet the principles and objectives of the plan.

2.4. Long-Term Measures and Strategies. A series of ten longterm policy measures/strategies are proposed in order to address energy security issues and concerns. These measures are summarized as follows:

(1) Promoting secure and stable energy supplies: The goal is to establish a "multilayered" energy supply system by creating an "optimal portfolio" of energy sources 
and securing them in a stable and economical manner. Self-sufficiency is to be enhanced by promoting domestic energy sources including nuclear power, renewable energy, and fossil fuels.

(2) Realizing an "advanced energy saving society": The goal is to create a "demand-side led energy supplydemand structure" and accelerate energy efficiency initiatives in all industry sectors in order to better "rationalize" the energy supply-demand structure and reduce greenhouse gas emissions.

(3) Accelerating the introduction of renewable energy: Increase the introduction of renewables to higher levels than in previous plans and to continue efforts to enhance electricity grids, pursue deregulation, and reduce power generation costs.

(4) Reestablishing nuclear energy policy: This strategy acknowledges the many failures in nuclear policy leading up to the Fukushima accident, leading to a loss of public trust. It puts restoration and reconstruction of Fukushima as the starting point for rebuilding energy policy. It acknowledges the stringent safety requirements of the newly established $\mathrm{NRA}^{3}$ and commits to restarting nuclear reactors that the NRA approves.

(5) Enhancing the environmental performance and efficient and stable use of fossil fuels: Improve structural and performance efficiencies in the thermal power sector.

(6) Promoting structural reforms in the energy sector: The goal is to realize a more efficient industrial structure in the energy sector. The 10 regionally based electricity monopolies are viewed as inadequate to respond to evolving electricity supply demands; therefore a more horizontally integrated structure is desired that allows new entities (including firms, local governments, and nonprofit organizations) to supply energy services.

(7) Enhancing the resilience of domestic energy supply networks: The aim is to enhance the capability of energy supply and demand-side systems to respond to crises and emergency situations.

(8) Further developing the secondary energy supplydemand structure: The goal is to develop additional methods of transporting and storing energy so as to diversify the secondary energy supply structure. A "hydrogen society" will also be promoted.

(9) Creating new energy services businesses, "smart communities," and expanded global markets for Japan's energy technologies: The aim is to leverage energy sector institutional reforms to trigger a "major transformation of the structure of the energy industry," establish new "smart communities," create new energy services companies, and increase participation by Japanese companies in international energy markets.

(10) Building comprehensive international energy cooperation frameworks: Japan will better respond to international developments affecting the energy sector through strategic energy cooperation with countries and organizations closely related to Japan.

\subsection{Other Key Elements}

Promoting Energy Technology Development. In order to reach the country's energy security and GHG emissions goals as well as reduce reliance on fossil fuels in the energy supplydemand structure, the plan calls for introducing "revolutionary" energy technologies throughout society. To achieve this, a long-term approach to energy R\&D as well as institutional reforms will be required. The government will therefore develop an energy technology roadmap by the summer of 2014 in order to carry out various technology development projects.

Enhancing Energy-Related Communication and Education. The government seeks public understanding of energyrelated issues and Japan's overall energy circumstances. It will therefore provide information and "conduct public relations" in an "objective and transparent manner based on facts and scientific knowledge." It also commits to establishing mechanisms to promote "two-way" communication and dialog, particularly with respect to nuclear power and its risks.

\section{Concepts and Analytical Framework}

The previous section outlined the key principles, objectives, and strategies in the SEP. In this section, we draw upon the literature on sociotechnical transitions and theories of the state in order to develop a framework for the analysis of the SEP. This framework will be used to explain the significance of the SEP for energy system change in Japan.

The structure of this section proceeds as follows. First, sociotechnical regime theory is reviewed, followed by a discussion of the literature related to sociotechnical transitions. A major premise of this study is that energy systems are sociotechnical systems, and so a macrolevel understanding of such systems and how they evolve is essential to interpreting the overall magnitude of system change called for in the SEP.

In order to understand the implications of specific policies and strategies contained in the SEP in greater depth, an analytical framework also requires a theory for interpreting the nature and magnitude of change at the meso- or policymaking level. This is achieved by presenting key concepts from the literature on theories of the state, with a specific focus on the concept of policymaking as social learning.

3.1. Sociotechnical Systems and Regimes. Energy systems can be conceptualized as sociotechnical systems (STS). STS are a special type of complex adaptive system where technologies and infrastructure, institutional arrangements (e.g., regulations, norms), social practices, and actor relationships (e.g., producer-consumer relations, industry associations, and public authorities) are mutually dependent and are embedded within the broader context of cultural paradigms, norms, values, and socioeconomic trends [17]. 
A refinement to the STS concept is that of a sociotechnical regime, which has been defined as a relatively stable configuration of institutions, technologies, and infrastructures [18]. What distinguishes a regime is its stability, which is derived from the linkages between heterogeneous groups of actors and institutions which are aligned and coordinated with each other through rules, routines, and practices [19].

Japan's energy system can be described as a regime. Its configuration has been shaped by the unique characteristics of its institutions, infrastructure, and technologies. Regimes, including Japan's energy regime, evolve along technological trajectories as rules and actor behavior move technological development in the same direction through incremental improvements, creating stability but also path dependence $[19,20]$.

3.2. Regime Transitions. Regime transitions are processes that involve a shift from the dominant regime to a new state of dynamic equilibrium by transforming rules, established technologies, and societal practices, a gradual process that can take many decades $[21,22]$. Studies of past energy transitions that have occurred throughout world history show that they are protracted affairs [23].

The transitions literature acknowledges that regimes are embedded within a broader environmental, social, and economic "landscape." The landscape includes slowly changing background variables such as political culture, social values and norms, worldviews and paradigms, the macroeconomy, and the natural environment [24]. Smith et al. [25] argue that the governance of regime transitions is a function of two factors: (1) selection pressures acting on the regime and the manner in which these selection pressures are expressed: Selection pressures may arise from various levels and take the form of government policies, regulations, liberalized markets, niche innovations, public debates, and so forth; (2) the coordination of resources in order to adapt to selection pressures: Resources include material resources and infrastructure as well as financial, social, and human (knowledge and skills) capital. Four types of transformation processes are derived from the combination of two variables: the availability of resources (i.e., whether internal or external to the regime) and the degree of coordination (i.e., low to high). The implications of this typology for the Japanese transition will be discussed in Section 5.

In this scheme, regime transitions can be differentiated by whether changes are planned (purposive) or autonomous (emergent). Planned transitions are coordinated through a "top-down" process of applying deliberate policy interventions. Transitions may also result from a "bottom-up" emergent process that is shaped autonomously by agents in the system and the system's own built-in rules $[24,26]$. Examples of autonomous change in energy markets may result from interfirm competition and technological change. In reality, energy transitions are a combination of both planned and autonomous changes.

Geels and Schot also propose four typologies of regime transition [27]. In this scheme, two variables play a critical role in determining the form the transition will take. First, the timing of landscape pressures is important as they relate to the state of technology and innovation in the regime. The transition path will depend on whether the state of innovation and new technologies are sufficiently developed when landscape pressures occur. Secondly, the nature of technology innovation and landscape pressures can either reinforce existing regime relationships or cause disruption to the regime. Landscape pressures that are reinforcing tend to stabilize and preserve the existing regime while those that are disruptive cause reconfiguration between new and existing elements leading to technological and structural changes. Four typologies arise from the combination of these two variables. Japan's transition pathway in relation to this scheme will be discussed in Section 5.

This paper primarily adopts the Smith et al. model since in our view it places a greater emphasis on agency versus structure in explaining the governance of transitions. This seems more suitable in the Japanese context given Japan's political and business culture and the state-centric role of government where there is a high level of coordination. Politics and the state have an important role to play in terms of committing resources, altering regulatory frameworks, balancing varied public interests, and acting as a "channel" for society to exert selection pressures designed to change the regime in desired ways [22]. At the same time, the Geels and Schot model can provide useful insights into the future transition pathway, given its emphasis on the relationship between the timing of landscape pressures and the influence of energy-related innovation and technology developments in Japan.

3.3. Social Learning, Policy Paradigms, and Change. It has been argued that policymaking is a form of reflection by policymakers on "what to do" on society's behalf in the face of uncertainty [28]. This in turn implies that policy is the output of a learning process and where, in pursuing the national interest, state actors "decide what to do without serious opposition from external actors" [29]. The concept of social learning asserts that ideas are central to policymaking and that policymakers work within an interpretive framework of ideas and mental models that specify the goals, instruments, and nature of the problems they are trying to address.

Hall [30] defined the concept of social learning as "a deliberate attempt to adjust the goals or techniques of policy in response to past experience or new information." The process of social learning has three essential elements. The first is that the most important influences on new policies are the policies that existed previously. Secondly, the key agents of policy change are those people who are either in privileged positions working in government or in positions where they can exert influence on government. Thirdly, while nonstate actors certainly influence the policymaking process, states have the capacity to act autonomously and independently of other social actors and societal pressures [30].

According to Hall, policymaking can be thought of as a process that typically involves three key variables: the goals and objectives that guide policy, the policy instruments that are used to achieve these goals, and the adjustments made to the policy instruments. Accordingly, Hall specified three orders of change in policymaking. First-order change involves 
adjustment of the means or instruments of policy and how existing policy tools are adjusted or fine-tuned. Second-order change is where the goals of policy remain the same but the instruments used to attain them are changed without changing a given policy paradigm. Third-order change involves changes in the goals and instruments of policy and a change in the paradigm itself. Policy paradigms shape the nature of policy choices and have a strong influence over policy development. This has been borne out in studies of China (see [31]) and the United Kingdom (see [32]). Paradigms tend to be resistant to change as long as they continue to fulfill expectations but they can break down in response to significant policy failures.

While first- and second-order changes involve social learning within the state, paradigm shifts result from social learning across society. However, while first-order changes are incrementalist and second-order changes are more strategic, neither of them necessarily lead to third-order changes. Changes to a policy paradigm require radical changes to the prevailing policy discourse and necessarily require political leadership, skillful persuasion, and effective marshalling of resources [30].

The perspective on social learning outlined here is particularly applicable to state-centric forms of governance and elevates the influence of the bureaucracy in policy change to at least that of politicians due to the continuity and stability of bureaucratic institutions. This perspective seems suitable for application to a country such as Japan where the state and bureaucracies in particular have played an influential role in energy policy development and change. The notion of orders of change and policy paradigms seems particularly suited to the analysis of a national energy plan given that such plans embody policies and strategies designed to effect change in the energy system.

3.4. Methodological Approach. The interpretive framework presented in this section integrates theories of sociotechnical change at the macrolevel of the energy system with a mesolevel perspective on social learning that emphasizes the role of goals, policy instruments, and paradigms in the policymaking process. This framework is applied to the content of the 2014 SEP as well as the policymaking process that led to its development in order to provide insights into the significance of the plan for energy system change. The analysis centers on the 2014 version of Japan's Strategic Energy Plan as published by the Japanese government in English.

In order to provide more in-depth insights into the development of the SEP and the role of Japan's bureaucracy in its formulation, a series of in-person semistructured interviews were conducted with senior government officials from the Ministry of Economy, Trade and Industry (METI) who are or were directly involved in the development and implementation of the SEP and related policies. Interviews were also conducted with officials with selected energy industry associations and public bodies that provided input to the formulation of the SEP. The interviews were conducted in person in late February and early March, 2016. Background information leading up to the formulation of the plan also relied on various analyses published in both Japanese and English.

\section{Results and Analysis}

4.1. Comparison of the 2014 SEP with Previous Energy Plans. Since the establishment of the Basic Act on Energy Policy, several national energy plans have been issued by the government. Here we compare the most recent plans with the 2014 SEP.

2006 NNES and 2007 BEP. The New National Energy Strategy of 2006 (NNES) [33] was crafted during a period where fossil fuel prices were rapidly rising and fears of resource competition, arising particularly from increasing Chinese demand, were of concern to Japan. The NNES was essentially a preliminary template for the 2007 BEP and was clearly focused on energy security. It was founded on 3 objectives:

(i) strengthening energy security

(ii) a comprehensive approach to both energy and environmental issues (i.e., sustainability)

(iii) a commitment to working with Asian nations to avoid resource competition.

The 2007 BEP included 4 key strategies [34]:

(i) Promotion of energy conservation and energy efficiency and establishing a resource-saving socioeconomic structure.

(ii) Diversification of energy sources with a particular focus on nuclear power and the nuclear fuel cycle.

(iii) Promotion of strategic and comprehensive measures for securing a stable supply of fossil fuels and uranium.

(iv) Engaging in energy diplomacy and environmental cooperation with other countries and supporting the independent development of resources overseas by Japanese companies.

2010 SEP. The 2010 version of the SEP reconfirmed the 3E's of Japanese energy policy but added two new goals that did not appear in previous plans. These were "energy-based economic growth" and "reform of the energy industrial structure." The plan states that Japan will "fundamentally change its energy supply and demand system by 2030." An explicit link to Japan's broader economic growth priorities was also added, stating that the plan was formulated so as to be "consistent with Japan's "New Growth Strategy."

Specific measures in the 2010 BEP included energy cooperation and resource diplomacy initiatives to increase Japan's self-sufficiency ratio; enhancing the supply structure by expanding renewables, promoting nuclear power, implementing low-carbon technologies, building the "world's most advanced interactive grid network by the 2020s," realizing a "low-carbon energy demand structure," developing smart grids and hydrogen infrastructure, support for energy technology and innovation, resource diplomacy, and measures to reduce carbon emissions. 
Even though the 2010 plan set reform of the energy industrial structure as a new goal, the plan itself failed to include any significant deregulation or structural reform measures. Other than promoting hydrogen use and some new technology programs, most the strategies and measures in the plan were incremental and directed toward expanding on existing policies and programs.

The 2014 SEP differs from the 2010 version in several important respects:

(i) It commits to major structural and institutional reforms with specific policies. Energy sector reforms are to act as a lever to promote competition, stimulate changes in the energy industrial structure, and promote new energy services businesses.

(ii) Nuclear power is to play a less prominent role in the future; its use is intended to be "minimized."

(iii) Renewables generation is targeted for significant expansion over previous SEPs and promoting distributed generation is added for the first time.

(iv) It commits to link all of Japan's regional electricity grids into a national grid system.

(v) A wider range of demand-side initiatives are emphasized and call for a "demand-led" energy structure.

(vi) Coal is affirmed as an important base-load energy source and clean coal technologies will be promoted in electricity generation.

(vii) Specific steps toward building a "hydrogen society" are highlighted.

(viii) Externally focused strategic energy security initiatives play a more prominent role.

(ix) A commitment to energy education and public engagement concerning energy-related issues is included for the first time.

In summary, the NNES and the 2007, 2010, and 2014 SEPs all share a primary focus on enhancing energy security. The NNES mentions building a "state-of-the-art energy supplydemand structure" and the 2010 SEP mentions "reform of the energy industrial structure." Although there are some similarities with the "multilayered, flexible, and diversified energy supply-demand infrastructure" of the 2014 SEP, both the NNES and the 2010 SEP incorporated policies that are best described as incremental. By contrast, the 2014 SEP takes a comprehensive and systematic approach to energy system change and includes specific policy goals and strategies designed to stimulate fundamental reform in Japan's industrial structure and energy institutions.

4.2. Relationship to Other Government Policies. The government clearly views energy system reform as a significant potential driver of new economic growth [35]. The Japan Revitalization Strategy (JRS), also known as the "Growth Strategy," was first released in June 2013 as part of the "threearrow" approach of "Abenomics" whose intent is to "put the economy back onto a full growth path." As such, the JRS represents the overarching plan for the "third arrow" of structural reforms. It contains various policies and actions with specific goals and performance measures and was revised in 2014 and 2015.

The Strategic Energy Plan of 2014 plays an important role within the JRS and the government's broader plans for "revitalizing" the Japanese economy. As part of the industry revitalization action plan within the JRS, energy sector reforms are positioned as contributing toward enhancing the international competitiveness of the industry sector. In particular, completing electric system reform "by 2020 at the latest" is highlighted as a key performance indicator. In addition, many of the strategies mentioned in the SEP are affirmed in the JRS as well and some include specific performance indicators. With an eye on the 2020 Olympics in Tokyo, the 2015 revision of the JRS adds an emphasis on developing distributed generation ("distributed energy resources") as a public-private project meant to showcase Japanese technology and know-how [36].

4.3. Content Analysis. In analyzing the narrative in the plan, a number of references to making transformational changes in Japan's energy system can be found. For example, the plan states a "major transformation of the structure of the energy industry to be triggered by institutional reforms" (SEP, p. 73). The plan refers to making "institutional reforms" and promoting "structural reforms" (i.e., oil refining, electricity, and gas markets) numerous times. The term "reform" appears 69 times mostly in reference structural reforms, while the term "institutional" appears in tandem with "reform" 15 times. According to METI officials, the term "structural reform" is used to refer to policies designed to change the energy industrial structure ${ }^{4}$ (i.e., energy utilities and energy companies). It is also understood to include the petroleum refining and retailing sector since METI wanted a more sustainable and efficient oil refining industry in light of steadily declining petroleum demand in Japan. This element of reform is also one that has not been seen in previous versions of the SEP.

The term "institutional reform" refers to deregulation and liberalization policies aimed primarily at the electricity sector since institutional reforms in the petroleum sector had already been undertaken in the 1990s. Since the electricity sector is still heavily regulated by the Electricity Business Act, institutional reforms were deemed as necessary. Thus, METI's perspective on institutional reforms includes the dismantling of the regional monopoly structure and the fixed price (regulated prices) system. ${ }^{5}$ Other institutional reforms include changes to the renewables policy, including a bill to amend the feed-in tariff (FIT) system.

4.3.1. Levels of Change in the SEP. Many of the policies and strategies mentioned in the SEP can be classified as firstorder changes since they build on existing strategies and plans but enhance them by reinforcing current programs (such as energy cooperation and resource diplomacy efforts, exploiting domestic nonrenewable resources, and enhancing energy efficiency), or increasing their scope (such as including energy efficiency requirements in the Top Runner program for residential and commercial buildings). Innovation and 
TABLE 1: METI budget allocations (billions of yen).

\begin{tabular}{lcccc}
\hline Item & FY2013 & FY2014 & FY2015 & FY2016 (requested) \\
\hline General account & 329.9 & 337.0 & 338.3 & 395.3 \\
Energy resources special account $^{\mathrm{a}}$ & 783.3 & 872.7 & 796.5 & 975.7 \\
Subtotal $_{\text {Supplementary budget for energy measures }}{ }^{\mathrm{b}}$ & 1113.1 & 1209.7 & 1134.7 & 1371.0 \\
Grand total & 93.0 & 351.5 & 382.6 & $\mathrm{~N} / \mathrm{A}$ \\
Energy-related only $(a+b)$ & 1206.1 & 1561.2 & 1517.3 & $\mathrm{~N} / \mathrm{A}$ \\
Change in energy-related budget over previous year & 876.3 & 1224.2 & 1179.1 & $\mathrm{~N} / \mathrm{A}$ \\
Share of energy-related budget to total budget & $\mathrm{N} / \mathrm{A}$ & $39.6 \%$ & $-3.7 \%$ & N/A \\
\hline
\end{tabular}

Source: METI (2016).

technology development is a strong theme running through the SEP and while the plan is short on details, many of these initiatives appear to be first-order changes that are directed toward strengthening or expanding existing policy initiatives.

The realization of a "hydrogen society" can be considered a second-order change. Achieving a "hydrogen society" was mentioned in the 2006 NNES and hydrogen infrastructure and technologies are also prioritized in the 2010 SEP. However, the 2014 SEP elevates the prominence of this goal and introduces a number of new policy instruments meant to achieve it including developing a comprehensive "roadmap" to coordinate efforts and investing in projects to produce hydrogen overseas for export to Japan. The creation of a hydrogen society clearly appears to be more of a technology development strategy rather than a paradigm-shifting vision for the future of Japan's energy system.

Strategies related to the acceleration of renewable energy sources are another example of second-order change. Japan had been promoting the introduction of renewables for many years through various programs with only marginal success up to 2012. With the introduction of the new FIT program in 2012, renewables (especially solar) capacity has rapidly increased. However, the SEP states that "higher levels" of renewable power will be pursued. In line with this change, the release of energy mix targets in 2015 set renewables generation targets significantly higher than the targets in previous plans [37]. The SEP also proposes a new policy instrument, the "Related Minister's Cabinet Meeting on Renewable Energy," to promote cooperation and coordinate efforts in support of renewables across ministries.

An example of third-order change is centered on creating a more efficient energy industry structure. Although steps toward partial liberalization in the electricity sector had been rolled out in previous years, the SEP affirms the recommendations of the 2013 Report of the Electricity System Reform Subcommittee which addressed a number of energy system vulnerabilities exposed after the triple disaster and developed a comprehensive three-step "roadmap" for electricity system reform. The SEP expands on this with a broad vision for the future energy industrial structure which it sees as moving from one that is vertically segmented by market to one that is horizontally integrated across energy segments. ${ }^{6}$ This is to be accomplished by "eliminating market barriers through institutional reforms," as well as the introduction of new technologies and management practices. This includes the "creation of comprehensive energy companies through market integration," allowing energy-related companies to enter each other's market segments.

A second example of third-order change is the creation of a demand-side led energy system. This is a new goal that includes some policy instruments not seen previously. The SEP talks about finding an "optimal energy supply-demand structure for Japan ${ }^{8}$." It mentions a number of problems with the current structure, including its lack of flexibility in providing demand-side pricing and services options ${ }^{9}$ and calls for end-user participation in the energy system. ${ }^{10}$ Enabling demand-side participation is seen as determining the type and scale of energy sources in the market (i.e., the energy mix) and enhancing system stability. This is to be achieved through strategies such as implementing demand-response systems, smart grid technologies, smart communities, and promoting a distributed energy system. ${ }^{11}$ This vision represents a major paradigm shift from a centralized, supply-side focused energy system to one that is distributed and demand-responsive. ${ }^{12}$ It also implies a much smaller role for government and the 10 regionally based General Electric Utilities (GEUs) in determining the energy mix, leaving this largely up to markets.

4.4. Resource Commitments to the Plan. In addition to the regulatory reforms and liberalization measures that have already been implemented, the government's commitment to energy system reform can be evaluated by looking at government budget allocations to programs and initiatives aligned with the goals and policies of the SEP.

Table 1 has been adapted from METI data and shows METI's annual budgets for FY2013-FY2016. In FY 2014, the same year the revised SEP was issued, METI's total energyrelated budget ${ }^{13}$ (including the supplementary budget) of $¥ 1,224$ billion was increased by almost $40 \%$ over the previous year and FY2015 budgets have been maintained at a similar level. A budget breakdown shows that the increases are closely aligned with the strategies and initiatives outlined in the SEP. In 2015, significant new funding has been allocated to measures to improve energy efficiency and conservation, expand renewables generation, develop domestic energy resources, build resilience in the energy supply chain, and conduct R\&D related to energy and environmental technology [38]. Based on METI's 2016 budget requests, it is likely that energy budgets will increase again. As a result, energyrelated budgets now represent about $78 \%$ of METI's total budget. 
Other ministries have requested increases for energyrelated programs as well. For FY2016, the Ministry of Environment (MOE) requested an increase of 175.7 billion yen for energy-related measures (i.e., energy conservation and renewables) representing a $62 \%$ increase over the 2015 budget request [39].

In addition to the various financial resources and incentives provided as noted above, the government also created several new coordinating organizations to facilitate the changes proposed in the SEP. Responsibility for nuclear power regulation was transferred from METI to the newly created and independent Nuclear Regulation Authority (NRA), while many aspects of electricity regulation were transferred to newly created independent agencies and organizations (e.g., OCCTO ${ }^{14}$ and $\mathrm{EGC}^{15}$ ).

In summary, the initiatives laid out in the 2014 SEP have been backed up by substantial new funding in government budgets as well as additional human and technical resources as embodied in several newly created regulatory bodies. While it is not possible to say whether these resource commitments are adequate to achieve the goals in the SEP or whether resources will be effectively utilized, it seems reasonable to conclude that these enhancements represent a significant source of external resources meant to facilitate the implementation of the SEP.

\subsection{Policymaking and the Development of the 2014 SEP}

4.5.1. Stakeholder Responses. The government faced a wide range of stakeholder pressures and reactions in the aftermath of the triple disaster which impacted upon its approach to the development of the 2014 SEP. We may usefully distinguish between external pressures (i.e., stakeholder reaction from outside of the energy system such as consumers and civil society groups) and internal pressures (i.e., including from energy utilities, companies, and energy industry associations).

The immediate response from the general public to the triple disaster was largely concerned with the risk of nuclear contamination, the government's ability to effectively deal with the disaster, and the need to restrict energy use in order to avoid rotating blackouts. As time went on, public concerns focused more on how TEPCO and the government were managing disaster recovery efforts as well as nuclear safety issues in general. Polls taken in the period following the disaster showed that the public was distrustful of the nuclear power industry and the government's nuclear safety measures and were opposed to the restart of nuclear reactors [40-42].

Many civil society groups generally adopted an antinuclear power stance. For example, the Consumers Union of Japan opposed the continued use of nuclear power and was against the government's plan to pass Fukushima decommissioning costs on to power producers fearing it would result in higher energy costs for consumers $[43,44]$. Others such as JREF, ISEP, and JFS ${ }^{16}$ as well as some in the academic community advocated for the rapid expansion of renewables to replace nuclear power.

On the other hand, Japan's export-oriented manufacturing industry began to suffer from higher power costs (as a result of high oil prices and increased fossil fuel imports) and its international competitiveness was put at severe risk. The "policy costs" of the government's postdisaster regulatory policies and the potential loss of relatively cheap nuclear power were of major concern to manufacturing companies [45].

Pressures from within the energy sector largely centered around preservation of the status quo. The nuclear power sector strongly advocated for the continued use of nuclear power in order to provide energy security and lower power costs, and the existing GEUs wished to maintain their regional monopolies and resisted liberalization of the electricity market. In its proposal to the energy mix committee under the Advisory Committee Natural Resources and Energy (ACNRE), Japan's most influential business association-the Keidanren-said that it was unrealistic for Japan to have ambitious renewables targets and that the reliance on nuclear power should be increased and proposed that renewables should make up no more than $15 \%$ of the power generation mix [46]. On the other hand, other companies such as telecommunications companies and firms outside the electricity sector advocated liberalization in order to expand their business activities and provide more retail options for consumers. The Japan Gas Association which represents natural gas distributors was generally favorable to changes that would open up opportunities for their members to sell electricity services bundled with their gas services. ${ }^{17}$

4.5.2. Development of the Plan. Ultimately, the loss of nuclear power capacity due to the shutdown of Japan's nuclear power plants for safety reviews and reevaluations, the higher power costs for consumers and manufacturers associated with replacing nuclear with coal and natural gas, and the sharp increase in GHG emissions from the expanded use of fossil fuels played a decisive role in prompting the government to begin a major review of its energy policies.

As early as October 2011, several months after the triple disaster, revisions to the $2010 \mathrm{BEP}$ were being discussed and considered by Advisory Committee Natural Resources and Energy, Fundamental Issues Subcommittee [47]. The subcommittee stated that, as a consequence of the disaster and the vulnerabilities it exposed, Japan's energy policy was "approaching a major turning point" and that a revised plan was to be formulated from a "zero-base." Furthermore, the committee stated that the energy supply structure needed to be "fundamentally revised" and that an "ideal" energy mix along with measures to achieve it would be required. In particular, the committee said that the ambitious targets for nuclear power made in the 2010 BEP would have to be fundamentally altered without eliminating nuclear power entirely, in order for the country to maintain its technical infrastructure and specially trained staff.

Despite the vulnerabilities exposed by the triple disaster and the deliberations of METI energy subcommittees, the Democratic Party of Japan (DPJ) government did not issue an early revision of the SEP, likely due to its preoccupation in dealing with disaster recovery and other urgent issues arising as a result of the triple disaster. After the election of the Liberal Democratic Party (LDP) in December 2012, the new Abe administration decided on January 25, 2013, to undertake a 
"zero-based review" of the previous administration's energy and environmental strategies for the purpose of establishing a "responsible energy policy which also ensures a stable supply of energy and reduced energy costs." At the same time, dependence on nuclear power generation would be reduced "to the extent possible" [48].

Meanwhile, deliberations on electricity system reforms had been proceeding for some time. The Electricity System Reform Expert Subcommittee ${ }^{18}$ was formed by METI in February 2012 and held 12 meetings, delivering a final report with recommendations on February 8, 2013. The committee's report (see [49]) provided a detailed analysis of the weaknesses of the Japanese electricity system. The report noted that electricity market and institutional reforms introduced starting in 1995 did manage to reduce electricity prices but that, despite these reforms, "no significant change has occurred in the market structure of the current electricity system." In particular, the regional monopoly system was singled out for being insufficiently competitive.

The report details a number of problems with Japan's electricity system that were revealed by the events surrounding the triple disaster including a lack of options for consumers to choose their own suppliers, the inability to utilize generation in merit order, the lack of connection of renewables to the grid, the need for a more diverse range of power sources, the lack of national grid integration, and the need for fair and neutral access to the electricity grid. The report stated that a stable and secure energy supply could not be assured simply by maintaining the vertically integrated regional monopoly supply system and that a "paradigm shift" in Japan's power supply structure would be necessary. The report concluded that major electricity reform efforts were required and provided detailed recommendations on changes [49]. Based on this report, the Abe Cabinet approved the Policy on Electricity System Reform on April 2, 2013, and made a number of recommendations including a three-step electricity liberalization plan $[49,50]$.

From the summer of 2013 METI officials began to be concerned about the growing number of energy security threats facing Japan, including the possibility of oil supply disruptions resulting from a threatened attack on Iran's nuclear facilities by Israel, the stability and security of energy supplies from the Middle East in general, and rising energy prices ${ }^{19}$. It was around this time that the government also began to consider stepping up efforts to obtain energy supplies from more secure sources and sea-lanes, particularly North America. In view of energy security threats, nuclear power was seen as essential to assuring that Japan had a diversified, stable, and robust domestic energy supply. But without a new energy plan, bureaucrats felt that they could not defend the policies they felt were necessary to address Japan's energy security issues from public criticism. METI officials felt they needed an "integrated policy management architecture" that incorporated clear policy principles, a kind of "constitution for energy policy ${ }^{20}$."

The process of producing the SEP normally involved a "bottom-up" process where various committees and subcommittees under ACNRE develop "policy packages" and then move them up the main committee (ACNRE) for discussion and integration. ${ }^{21}$ However, METI felt that the usual subcommittee process would "not be useful" in the turbulent and politically charged atmosphere that prevailed after Fukushima. It was therefore decided to engage only with the main ACNRE committee. ${ }^{22}$ METI's strategy for the SEP was to develop a comprehensive policy framework built around a set of principles, thus minimizing the opportunity for special interests to influence the outcome. Once the plan received Cabinet approval, it could not be derailed. ${ }^{23}$

Before the work on developing the SEP began, a number of energy policy initiatives had already begun under the DPJ government in response to the urgency of the issues facing the nation after the triple disaster. This included the creation of the NRA, the work of the Electricity System Reform Expert Subcommittee, the introduction of the new feed-in tariff (FIT) program for renewables, and other measures. The SEP had to incorporate these ad hoc measures within a comprehensive energy policy framework.

METI planning officials were charged with developing a draft of the plan, working in consultation with the Chairman of the ACNRE, Mr. Akio Mimura (former Chairman of Nippon Steel Corp.). The recommendations from the Report of the Electricity System Reform Expert Subcommittee would play a central role in the reforms embodied in the plan. Actual discussions began on August 27, 2013, after which the Strategic Policy Committee ${ }^{24}$ working directly with ACNRE developed the "Draft Opinions on the Basic Energy Plan" document [51]. A consensus on a first draft of the plan (developed largely by METI officials) was reached by the committee on December 13, $2013^{25}$, after which the document was released for public comment. After the public comment period ended, a final draft of the plan was completed by METI on February 25, 2014, and then moved through the political process. After receiving approval by the Cabinet, the final document was released to the public on April 11, 2014.

In summary, the policy environment for energy in the period after the triple disaster was contentious and turbulent. The government decided on a top-down, abbreviated process in formulating the SEP, bypassing potential roadblocks, and quickly moving the document to Cabinet for approval. Unlike previous Strategic Energy Plans that were consolidated from the work of a large number of specialized subcommittees over a long period of gestation, the 2014 plan was developed relatively quickly by a very small group within ANRE's policy planning group in consultation with the ACNRE committee alone. This fact helps explain why the 2014 plan reads as a more cohesive and comprehensive document, reflecting the priorities of METI in the post-Fukushima period where energy security concerns and a sense of urgency heavily influenced the policy environment in which the plan was developed.

4.6. Structural Changes in Japan's Energy Sector. While it is still early to make definitive conclusions about whether the policies and objectives in the SEP are achieving their intended results, there is strong evidence that the policies introduced in 
the period leading up to and after the release of the SEP have already stimulated significant structural and institutional changes in Japan's energy sector.

Following the introduction of a renewables feed-in tariff and the establishment of new regulatory institutions, changes in industry structure have begun to reshape energy markets. An unwritten rule among the regional utilities not to compete with each other was broken when Chubu Electric, a regional GEU, purchased Diamond Power Corp., a Tokyo-based independent electricity supplier.

New entrants into Japan's electricity supply market have risen sharply in response to the establishment of the new FIT scheme for renewable power. From only about 30 new companies in 2010, the number of new companies entering the power market soared to over 3,200 in 2014 [52].

The regional monopoly structure is now being gradually dismantled through a three-step series of electricity reforms that saw full retail choice for electricity customers in 2016 and unbundling of generation and transmission by 2020 . The number of new entrants into the retail electricity market has also sharply increased. Electricity reforms have led to more than 300 new entrants and existing firms are forging new partnerships in order to offer combinations of electricity, gas, telecom, and other services to customers. This includes gas suppliers such as Tokyo Gas and Osaka Gas, oil wholesalers such as JX Nippon Oil \& Energy, and telecom carriers such as SoftBank [53]. In a sign that Japanese consumers are looking for ways to cut costs or enhance the services they receive, about 54,000 power customers decided to switch power providers as companies compete to lower prices [54].

Following the introduction of a renewables feed-in tariff in 2012, renewables capacity and market share have sharply increased. Government data from METI indicates that the share of solar PV has risen to $4.3 \%$ of electricity production during 2016, which represents a sharp increase over 2015 when solar PV represented only $2.7 \%$ of production [55].

\section{Discussion}

Several scholars have argued that the triple disaster served as a "exogenous shock," moving Japan's energy system toward a new postdisaster mode [56] or even toward a "low-carbon transition" [14]. After the disaster, many Japanese observers viewed the catastrophe as an opportunity for a major transition in the energy system [57]. Indeed, the SEP itself mentions that the triple disaster caused "drastic changes" in the circumstances surrounding Japan's energy system leading to a "new direction" for Japanese energy policy. The government itself has stated that the SEP represents a fundamental rethink of Japanese energy policy undertaken from a "zero-based review."

From the results and analysis provided in this study, we can summarize the key aspects of the 2014 SEP as follows:

(i) The dismantling of the regional monopoly electricity supply structure and the system of regulated prices.

(ii) The "top-down" government-led process that was employed to develop the SEP and secure its approval. (iii) The comprehensive and systematic approach to addressing system-wide vulnerabilities and issues as reflected in the plan.

(iv) Third-order changes that point to significant changes to the energy industrial structure and energy-related institutions.

(v) Significant budget enhancements to support programs that are aligned with the objectives of the SEP.

(vi) Specific long-term goals and targets included in the plan or in closely related policy documents (such as the electricity mix targets issued in 2015).

The shock of the triple disaster opened up a window of opportunity in Japan's policy environment for a fundamental change in Japan's energy policy. ${ }^{26}$ The systematic and comprehensive approach taken in the SEP suggests that its development was underpinned by rapid social learning by politicians and bureaucrats who perceived a strong urgency in dealing with the severe energy security vulnerabilities arising in the aftermath of the triple disaster. The rapidly evolving policy environment surrounding energy became conducive to a reframing of the way in which the energy system could be conceived.

The 2014 SEP allows for major reforms to the energy industrial structure and energy institutions that were not possible in previous plans due to the predominance of the regional monopoly electricity structure that had served as a fundamental policy paradigm for over 60 years. This represents a major policy paradigm shift-from a centralized, supply-side focused energy system to a distributed and demand-responsive ${ }^{27}$ system characterized as a "multilayered and diversified flexible energy supply-demand structure." Despite resistance from the entrenched interests of the GEUs and the nuclear power sector, the Strategic Energy Plan of 2014 embodies policies that would potentially result in the most comprehensive and significant changes to the energy system since the regional monopoly system was established in the early 1950 s.

Japan's Energy Transition. Based on the analysis provided in this study and employing the model of transition contexts from Smith et al., we can classify the Japanese transition as a purposive (or planned) transition. This context is characterized by a high level of coordination at the regime level, combined with the availability of external resources. In this case, coordination is provided principally by government through policy direction, regulation, advisory committees, and so forth but also by the energy industry itself, mainly through industry associations and autonomous interactions. Significant new resources are also being made available to support adaptation mainly through government budget enhancements (including for innovation and technology development), new organizational structures, and subsidies and financial incentives to industry. This type of transition also implies that it was planned to reflect a broader set of interests beyond just the energy sector, and indeed the outcomes envisioned for the SEP are meant to produce positive impacts on 
the macroeconomy, the manufacturing sector, the business community, and consumers.

Considering the priority given to energy security (consistent with previous plans) and its vision for a "multilayered and diversified flexible energy supply-demand structure," the 2014 SEP can best be characterized as a planned "energy transition" rather than as a "low-carbon transition." Low-carbon transitions imply a paradigm driven principally by climate change imperatives. However, as we have demonstrated in this study, the majority of the policies and third-order changes embodied in the SEP support an energy security driven paradigm, with economic and environmentrelated strategies being confined to first- and second-order changes.

In terms of the future of the transition, the typologies proposed by Geels and Schot can also provide a useful interpretive tool. Their reconfiguration pathway is characterized by a reconfigured architecture (or structure) which arises as a result of innovations and technological changes that create new combinations of new and old elements [27]. These changes, combined with landscape pressures, can cause a major reconfiguration of the regime. In the case of postdisaster Japan, the various landscape and selection pressures described in this study are occurring at a time when energy innovations critical to sustaining a competitive, low-carbon energy system without nuclear power have yet to become sufficiently feasible from either an economic or technical standpoint. In other words, Japan is currently unable to simultaneously produce competitively priced, affordable electricity while at the same time ensuring energy security and staying on track to meet its GHG emissions targets.

At this point in time, the basic structure or architecture of Japan's energy system remains similar to the way it was before the triple disaster, except for the loss of most nuclear power capacity - a capacity that is likely to take many years to return to predisaster levels, if ever. However, as we have noted above, the last two years have provided empirical evidence suggesting that the structure of Japan's energy regime has in fact begun changing. As the policies embodied in the SEP interact with regime actors and innovations within the system, Japan's energy system is likely to evolve further, perhaps along a path similar to the one the government has envisioned. As regime actors, including electricity generators, gas distributors, and retailers contend with both internal pressures (e.g., enhanced competition, changing regime relationships) and external pressures (e.g., government policies and regulations, global energy markets), changes in technologies, end-user behaviors, and business practices are likely to stimulate further structural changes and reconfigurations within the Japanese energy system. Other changes in the market are likely to follow as new market entrants step up the competition. The pace is likely to accelerate as the year 2020 and the final phase of electricity and gas reforms approaches.

Geels and Schot note that, in the reconfiguration pathway, new regimes evolve out of old ones, rather than by overturning the existing regime. This pathway seems most applicable to the case of Japan because Japanese energy businesses and government policymakers clearly envision a gradual transition to a "multilayered, flexible, and diversified energy supply-demand structure" over the course of the next twenty years. As time goes on, the government will need to continue to calibrate its policies in response to unplanned and unexpected developments and as the system responds (or fails to respond) to desired outcomes. While the SEP does call for introducing "revolutionary" energy technologies throughout society, the goals and strategies in the plan clearly envision building on existing structures while taking a systematic approach to promoting further structural changes over time.

\section{Conclusion and Policy Implications}

This study has attempted to demonstrate that the Strategic Energy Plan of 2014 embodies policies that would potentially result in the most comprehensive and significant changes to Japan's energy system in over 60 years.

Political agency has played a critical role in stimulating the transition while setting the stage for further institutional and structural changes in Japan's energy sector. Japan's transition is highly coordinated and resourced and has been driven from the top down. However, it is not clear that the social learning acquired by government policymakers in the postdisaster period is shared by the general public, particularly with respect to nuclear power issues. It remains highly uncertain whether a societal consensus on this issue can or will be achieved. This is a potential risk to achieving the paradigm shift implied in the plan.

While certain structural changes in Japan's energy system are already evident, the plan implies that the transition to a new structure will take place gradually. The current energy regime consists of very substantial investments in fossil fuel and nuclear infrastructure that is difficult to change or abandon. The building of new transmission lines, new nuclear power plants, grid storage, and hydrogen infrastructure will also be very costly, lasting many years. While the government remains a strong advocate for dismantling Japan's vertically integrated and regionally based monopoly electricity structure, it is also sensitive to the need to maintain stable, reliable, and affordable supplies of power as the transition proceeds and does not wish to weaken the incumbent utilities so much that they become unviable. ${ }^{28}$ Unlike some countries and regions, Japan has no electricity interconnections with neighboring countries it can rely on should supplies become unreliable. Thus, we can expect that the government will intercede to ensure the transition proceeds at a pace that does not lead to instability in the market.

While Japan's energy transition may well proceed accordingly to plan, the lessons learned from electricity and gas market liberalization in other countries suggests that new obstacles will appear, targets may be missed, and policies may not fulfill their intended purpose. Liberalized markets do not always evolve in ways intended by government planners. Considering the shift from a highly regulated system to one that is largely market-based, the unleashing of competitive forces is likely to make energy system developments much more unpredictable.

One particularly difficult challenge for the government will be how to achieve electricity mix targets in a liberalized market environment. In a liberalized system, achieving 
electricity mix targets and ensuring that capacity additions come online in time to match demand requirements is an important consideration. Yet a diversified electricity mix is critical to Japan's stated objective of creating a "multilayered" energy supply-demand structure while maintaining energy security and will also have significant implications for Japan's international climate change commitments. METI officials say in response that they will continue to monitor market developments closely, make adjustments to policy instruments when necessary, and help shape change rather than directly control it.

\section{Conflicts of Interest}

The authors declare that there are no conflicts of interest regarding the publication of this paper.

\section{Endnotes}

1. The terms "Basic Energy Plan" (BEP) and "Strategic Energy Plan" (SEP) are interchangeable. The Japanese government's English translation uses "Strategic Energy Plan" which is the term we use in this study.

2. The term "Basic Energy Plan" and "Strategic Energy Plan" are interchangeable, with the latter being the government's preferred English translation since 2010.

3. NRA, Nuclear Regulation Authority

4. Based on interviews with METI officials.

5. Based on interviews with METI officials.

6. SEP, p. 60

7. ibid., p. 73,74

8. ibid. p. 6

9. ibid. p. 12

10. ibid. p. 16

11. ibid. p. $42,66,75$

12. ibid. p. 19-20, 40-41

13. The "energy-related" figures given here do not include allocations related to Fukushima reconstruction and two special accounts for patents and trade reinsurance.

14. OCCTO, Organization for Cross-Regional Coordination of Transmission Operators

15. EGC, Electricity and Gas Market Surveillance Commission

16. JREF, Japan Renewable Energy Foundation (now called Renewable Energy Institute), ISEP, Institute for Sustainable Energy Policies, JFS, Japan for Sustainability.

17. Based on an interview with Japan Gas Association officials.

18. The committee was chaired by Motoshige Ito, a professor of economics at the University of Tokyo, and the 10 other members who were mostly academics from various Japanese universities.

19. Based on interviews with METI officials.
20. Interview with a senior METI official directly involved with compiling the Strategic Energy Plan.

21. As of April 2014, there were 36 such committees under ACNRE. The minutes of committee deliberations are normally made available to the public.

22. Interview with a senior METI official directly involved with compiling the Strategic Energy Plan.

23. Interview with a senior METI official directly involved with compiling the Strategic Energy Plan.

24. The Strategic Policy Committee is the most important committee under ACNRE and can be considered as a functional part of the ACNRE.

25. Interview with a senior METI official directly involved with compiling the Strategic Energy Plan.

26. Interview with a senior METI official directly involved with compiling the Strategic Energy Plan.

27. ibid. p. 19-20, 40-41

28. Based on interviews with METI officials.

\section{References}

[1] METI, "Cabinet Decision on the New Strategic Energy Plan 2014,” http://www.meti.go.jp/english/press/2014/0411_02.html, 2016.

[2] J. S. Duffield and B. Woodall, "Japan's new basic energy plan," Energy Policy, vol. 39, no. 6, pp. 3741-3749, 2011.

[3] Y. Kobayashi, "Enhancing energy resilience: challenging tasks for japans energy policy," Center for Strategic and International Studies; 2014.

[4] D. V. Vivoda, Energy Security in Japan: Challenges After Fukushima, Ashgate, 2014.

[5] V. Vivoda and G. Graetz, "Nuclear policy and regulation in japan after fukushima: navigating the crisis," Journal of Contemporary Asia, vol. 45, no. 3, pp. 490-509, 2014.

[6] K. Koyama, "Japan's post-fukushima energy policy challenges," Asian Economic Policy Review, vol. 8, no. 2, pp. 274-293, 2013.

[7] J. Meltzer, After fukushima: what's next for japan's energy and climate change policy?2011.

[8] P. J. Scalise, "Hard choices: Japan's post-fukushima energy policy in the 21st century," in Natural Disaster and Nuclear Crisis in Japan, J. Kingston, Ed., Routledge, 2012.

[9] V. Vivoda, “Japan's energy security predicament post-Fukushima," Energy Policy, vol. 46, pp. 135-143, 2012.

[10] M. Hayashi and L. Hughes, "The policy responses to the Fukushima nuclear accident and their effect on Japanese energy security," Energy Policy, vol. 59, pp. 86-101, 2013.

[11] M. Harada, T. Ichikawa, H. Takagi, and H. Uchida, "14-Building a hydrogen infrastructure in Japan A2 - Veziroğlu, Michael BallAngelo BasileT," in Compendium of Hydrogen Energy, vol. 4, pp. 321-335, Woodhead, Oxford, 2016.

[12] N. Behling, M. C. Williams, and S. Managi, "Fuel cells and the hydrogen revolution: Analysis of a strategic plan in Japan," Economic Analysis and Policy, vol. 48, pp. 204-221, 2015.

[13] T. Kuramochi, "Review of energy and climate policy developments in Japan before and after Fukushima," Renewable and Sustainable Energy Reviews, vol. 43, pp. 1320-1332, 2015. 
[14] T. Wakiyama, E. Zusman, and J. E. Monogan III, "Can a low-carbon-energy transition be sustained in post-Fukushima Japan? Assessing the varying impacts of exogenous shocks," Energy Policy, vol. 73, pp. 654-666, 2014.

[15] S. Cornot-Gandolphe and C. Mathieu, "Japan's Energy and Climate Policy: Towards Dispelling the Uncertainties. Institut Francais des Relations Internationales (IFRI)," 2015.

[16] T. N. Srinivasan and T. S. Gopi Rethinaraj, "Fukushima and thereafter: Reassessment of risks of nuclear power," Energy Policy, vol. 52, pp. 726-736, 2013.

[17] H. Rohracher, "Transforming energy systems toward sustainability: critical issues from a socio-technical perspective," Int J Environ Technol Manag, vol. 9, pp. 144-161, 2008.

[18] A. Rip and R. Kemp, Technological change, Battelle Press, 1998.

[19] F. W. Geels, "Technological transitions as evolutionary reconfiguration processes: A multi-level perspective and a case-study," Research Policy, vol. 31, no. 8-9, pp. 1257-1274, 2002.

[20] F. W. Geels, "From sectoral systems of innovation to sociotechnical systems: Insights about dynamics and change from sociology and institutional theory," Research Policy, vol. 33, no. 6-7, pp. 897-920, 2004.

[21] J-P. Voss and B. Bornemann, "The politics of reflexive governance: challenges for designing adaptive management and transition management," in Ecol Soc, vol. 16, 9 edition, 2011.

[22] J. Meadowcroft, "What about the politics? Sustainable development, transition management, and long term energy transitions," Policy Sciences, vol. 42, no. 4, pp. 323-340, 2009.

[23] V. Smil, Energy transitions: history, requirements, prospects, vol. 1, ABC-CLIO, prospects, 2010.

[24] F. Berkhout, A. Smith, and A. Stirling, "Socio-technological regimes and transition contexts," Syst Innov Transit Sustain Theory Evid Policy Edw Elgar Chelten, pp. 48-75, 2004.

[25] A. Smith, A. Stirling, and F. Berkhout, "The governance of sustainable socio-technical transitions," Research Policy, vol. 34, no. 10, pp. 1491-1510, 2005.

[26] J. Simmie and R. Martin, "The economic resilience of regions: towards an evolutionary approach," Cambridge Journal of Regions, Economy and Society, vol. 3, no. 1, pp. 27-43, 2010.

[27] F. W. Geels and J. Schot, "Typology of sociotechnical transition pathways," Research Policy, vol. 36, no. 3, pp. 399-417, 2007.

[28] H. Heclo, Modern Social Politics in Britain and Sweden, Yale University Press, 2nd edition, 1974.

[29] P. M. Sacks, G. A. Dorfman, W. Grant et al., "State structure and the asymmetrical society: an approach to public policy in britain," Comparative Politics, vol. 12, no. 3, p. 349, 1980.

[30] P. A. Hall, "Policy paradigms, social learning, and the state: the case of economic policymaking in Britain," Comparative Politics, vol. 25, no. 3, pp. 275-296, 1993.

[31] P. Andrews-Speed, "The Institutions of Energy Governance in China," in Cent Energy Pet Miner Law Policy, pp. 1-49, 2010.

[32] D. Helm, The New Energy Paradigm, Oxford University Press, 2007.

[33] METI, "New National Energy Strategy. Agency for Natural Resources and Energy," Japan; 2006.

[34] S. Itoh, "Japan's energy strategy and development of energy cooperation in the Asia-pacific," in ERINA Rep, vol. 77, pp. 3548, 2007.

[35] METI, "METI's mission. Ministry of Economy, Trade and Industry of Japan (METI)," 2014.
[36] Cabinet Office (Kantei) of Japan, Japan Revitalization Strategy (2015 revision), Cabinet Office, Government of Japan, 2015.

[37] METI, "Long-term Energy Supply and Demand Outlook (Energy mix targets)," Ministry of Economy, Trade and Industry of Japan (METI); 2015.

[38] METI, METI FY2015 Budget 2015. http://www.meti.go.jp/english/ aboutmeti/policy/index.html (accessed February 8, 2016).

[39] Kankyō Business Online. Ministry of the Environment requesting an increase of 62\% in its FY 2016 budget for energy conservation and renewable energy (Japanese) 境ビジネスオン ライン 2015. http://www.kankyo-business.jp/news/011232.php (accessed February 13, 2016).

[40] A. Shimbun, Asahi Shimbun poll 2011 http://yukokulog.blog129 .fc2.com/blog-entry-542.html (accessed July 22, 2015).

[41] A. Shimbun, $80 \%$ distrust government's nuke safety measures 2012.http://ajw.asahi.com/article/behind_news/social_affairs/ AJ201203130031.

[42] A. Shimbun, http://ajw.asahi.com/article/0311disaster/fukushima/ AJ201403180058.

[43] Consumers Union of Japan, CUJ Resolutions at the 42nd Annual Meeting in June, 2015 - Consumers Union of Japan 2015. http://www.nishoren.org/en/? $\mathrm{p}=1668$ (accessed April 25, 2017).

[44] Consumers Union. Do Not Shift Nuclear Power Plant Related Costs to Our Electricity Bills - Consumers Union of Japan 2017. http://www.nishoren.org/en/?p=1840 (accessed April 25, 2017).

[45] R. Kilisek, ““Policy Costs” Impact Japan's International Competitiveness. Break Energy, 2014," Energy “Policy Costs” Impact Japan's International Competitiveness. Break Energy 2014. http:// breakingenergy.com/2014/03/10/energy-policy-costs-impactjapans-international-competitiveness/.

[46] Carbon Pulse. Japan business lobby wants scaled-back renewables target in 2030 plan - Carbon Pulse 2015. http://carbonpulse.com/2781/ (accessed February 12, 2016).

[47] METI, Major discussion points toward the establishment of a new "Basic Energy Plan for Japan.” Ministry of Economy, Trade and Industry of Japan (METI), 2011.

[48] METI, Annual Report on Energy, Ministry of Economy, Trade and Industry of Japan (METI), 2013.

[49] METI, Report of the Electricity System Reform Expert Subcommittee, Ministry of Economy, Trade and Industry of Japan (METI), 2013.

[50] ANRE, “Japan's Electricity Market Deregulation," METI (ANRE), 2015.

[51] IEEJ, IEEJ e-Newsletter, No. 29, 2014.

[52] Japan for Sustainability, New Power Companies Soar in Japan in 2014, Increase of 1.8 times from 2013. JFS Jpn Sustain 2015, http://www.japanfs.org/en/news/archives/news_id035401.html (accessed February 13, 2016).

[53] Japan Times, "Power retail deregulation," Jpn Times 2016.

[54] Nikkei Asian Review. Japan's electricity deregulation: 54,000 clients jump to other power companies. Nikkei Asian Rev 2016.

[55] Renewable Energy Institute, Renewable Energy Institute 2017, http://www.renewable-ei.org/en/ (accessed April 26, 2017).

[56] M. Aoki and G. Rothwell, A Comparative Institutional Analysis of the Fukushima Nuclear Disaster: Lessons and Policy Implications, Social Science Research Network, Rochester, NY, USA, 2012.

[57] R. J. Samuels, Disaster and Change in Japan, Cornell University Press, Ithaca, NY, USA, 2013. 


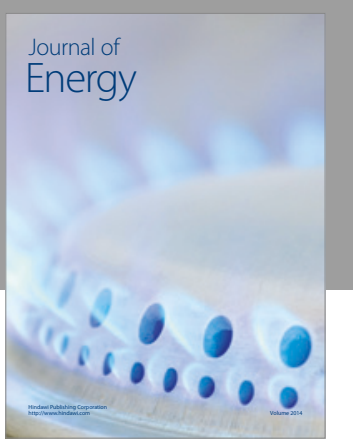

Journal of

Industrial Engineering
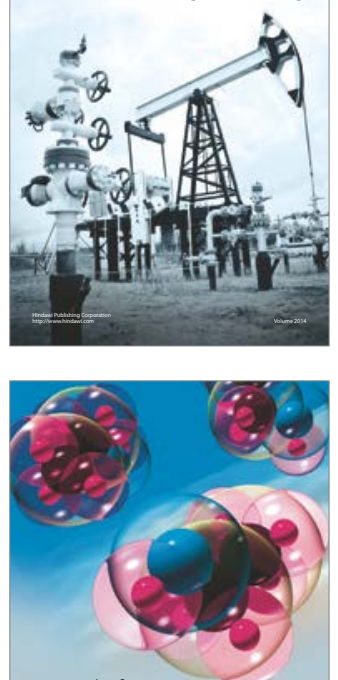

Fuels
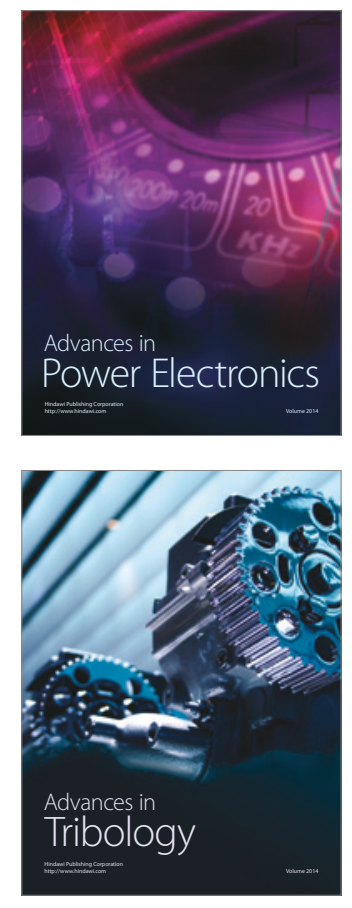
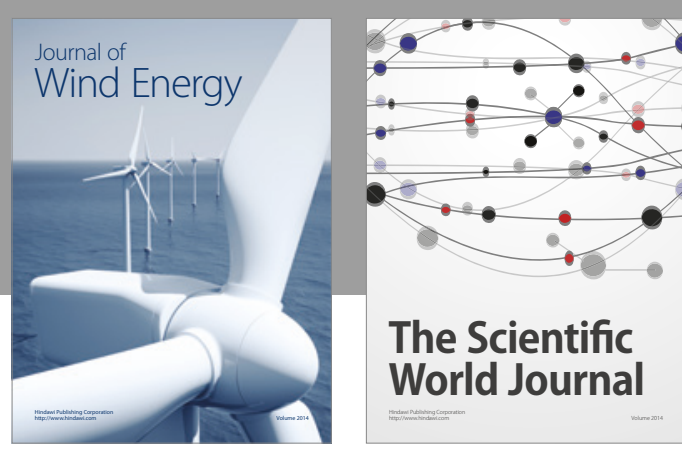

The Scientific World Journal
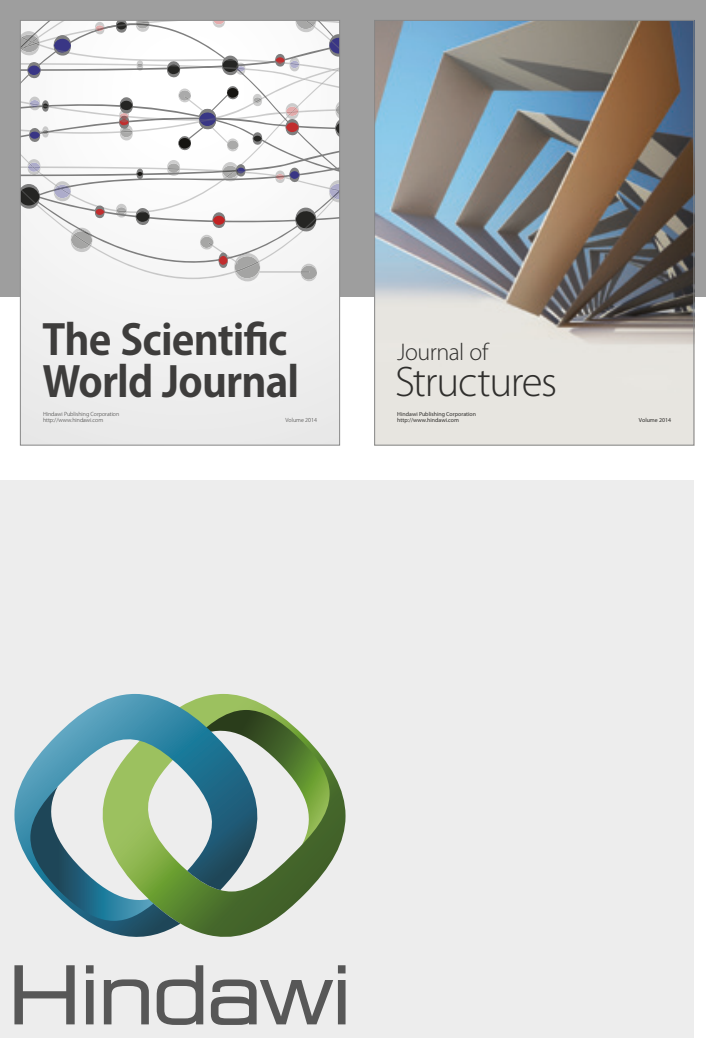

Submit your manuscripts at

https://www.hindawi.com
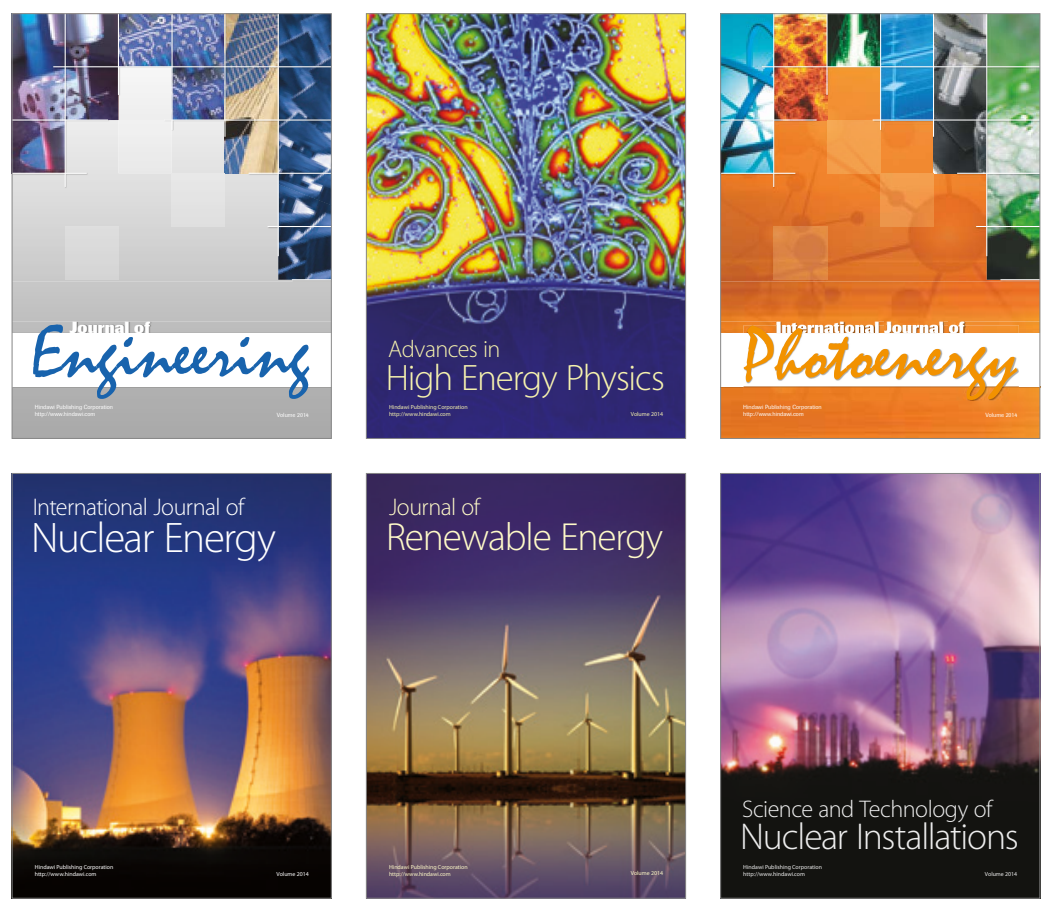

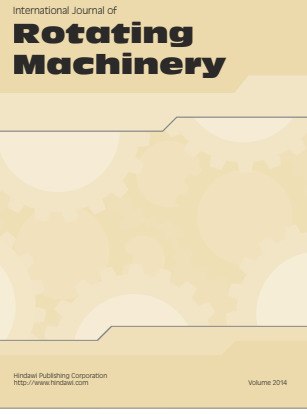

Journal of

Petroleum Engineering

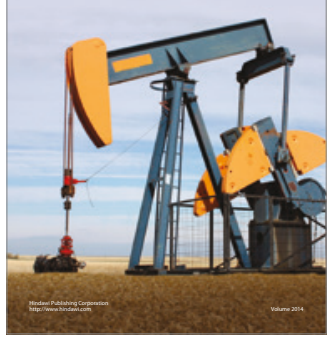

Journal of
Solar Energy
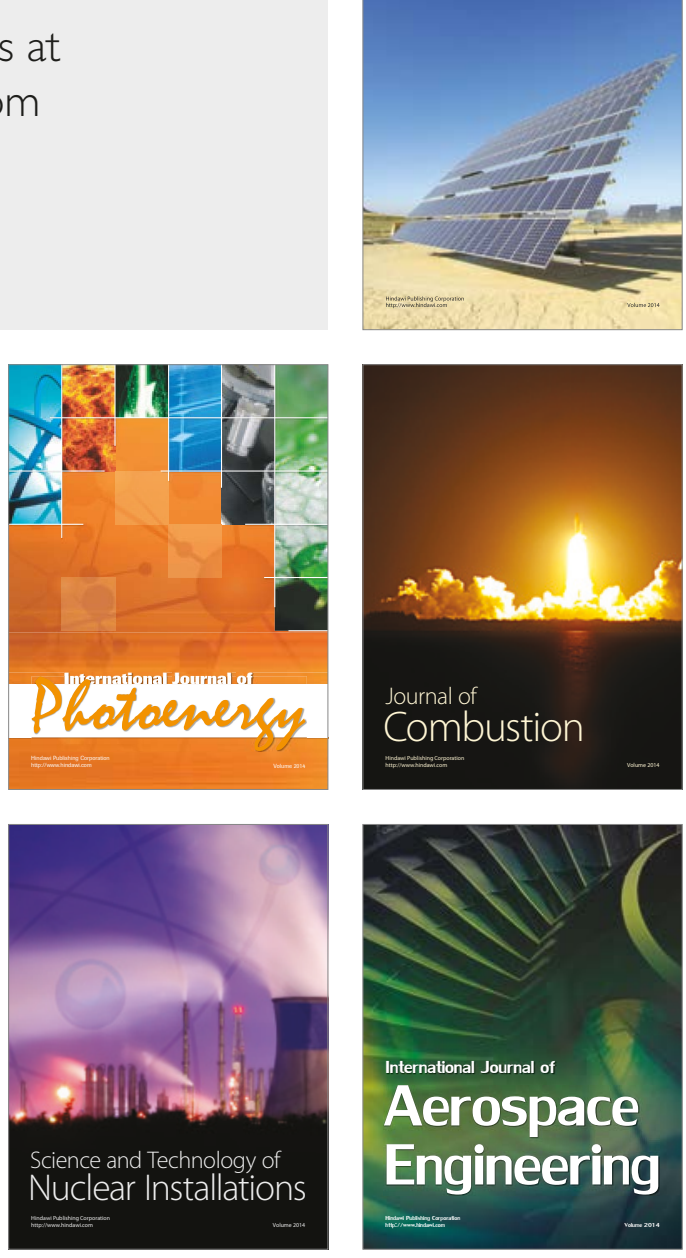